\title{
Transcriptional activation by the pseudorabies virus immediate early protein
}

\author{
Katherine J. Martin, ${ }^{1}$ James W. Lillie, ${ }^{2}$ and Michael R. Green ${ }^{1}$ \\ Department of Biochemistry and Molecular Biology, Harvard University, Cambridge, Massachusetts 02138 USA
}

\begin{abstract}
The pseudorabies virus immediate early (IE) protein is a potent, promiscuous activator of viral and cellular gene transcription. The promiscuous action of IE protein has led to the suggestion that it functions by an unusual mechanism. Here, we show that IE protein has the two essential features of a typical cellular activator: (1) a transcriptional activation region, and (2) a separable region that directs IE protein, or an unrelated activation region, to the vicinity of the promoter. We map the IE protein activation region to 34 amino acids, demonstrate that it is comparable in strength to the strongest known activation region, and show that it is required for the transcriptional activity of the intact IE protein. The 34-amino-acid IE protein activation region is highly acidic. We provide evidence that it uses the same cellular target as an unrelated acidic activator and a different target from that of a nonacidic activator. Our results provide insight into the function of promiscuous eukaryotic transcriptional activators.
\end{abstract}

[Key Words: Pseudorabies virus; IE protein; transcriptional activation; squelching]

Received September 6, 1990; revised version accepted October 17, 1990.

Pseudorabies virus, a member of the herpes virus family, expresses an immediate early (IE) protein that is required to activate early viral gene transcription (Ihara et al. 1983). The pseudorabies IE protein and the homologous IE protein of herpes simplex virus (HSV), ICP4, can also activate many additional genes (for review, see Tevethia and Spector 1989). For example, IE protein activates transcription of the early genes of the unrelated adenovirus and, remarkably, does so more efficiently than the normal activator of these genes, the adenovirus Ela protein (Feldman et al. 1982; Tremblay et al. 1985). IE protein also activates, among others, the cellular $\beta$-globin gene (Green et al. 1983), the human immunodeficiency virus-1 long terminal repeat (HIV-1 LTR; Yuan et al. 1989|, and even genes transcribed by RNA polymerase III (Gaynor et al. 1983; Ahlers and Feldman 1987). Because these different genes have no common promoter element, it would appear that activation by IE protein is highly promiscuous. On this basis, it has been suggested that IE protein functions in a manner fundamentally different from that of cellular transcriptional activators (for review, see Berk 1986).

The pseudorabies IE protein is similar in several respects to the adenovirus Ela protein. First, both Ela and IE proteins activate transcription of adenovirus early genes, and in fact, IE protein can substitute for Ela pro-

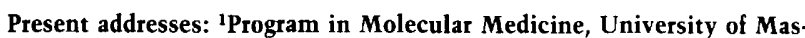
sachusetts Medical Center, Worcester, Massachusetts 01605 USA, ${ }^{2}$ AMIRA, Inc., Worcester, Massachusetts 01605 USA. tein in an adenovirus infection (Feldman et al. 1982, Tremblay et al. 1985). Second, both IE and Ela proteins can activate transcription of a variety of viral and cellular genes (for review, see Berk 1986). Third, neither Ela nor IE protein is a typical sequence-specific DNAbinding protein.

The adenovirus Ela protein has been analyzed extensively. Recent studies show that like a typical cellular activator, Ela protein functions at the promoter and contains at least two functional domains: a potent transcriptional activation region and a promoter-targeting region (Lillie and Green 1989). The promoter-targeting region appears to function by interacting with a cellular DNA-binding protein, ATF-2 (Liu and Green 1990). The ATF-2-Ela interaction can direct Ela protein to the adenovirus early promoters, which contain ATF-binding sites. The activation region of Ela protein appears to interact with the basic transcriptional machinery through a cellular "adaptor," an auxiliary transcription factor not used by acidic activators (Martin et al. 1990).

Here, we show that like Ela protein, the pseudorabies virus IE protein has the two essential properties of a typical cellular activator. IE protein has a potent transcriptional activation region, which is probably of the acidic class, and a separable region required for promoter targeting. We show further that both activities are critical for the function of the intact IE protein.

Our results, in conjunction with other studies (Cromlish et al. 1989), explain how eukaryotic transcriptional activators can function promiscuously. 


\section{Results}

IE protein contains a transcriptional activation region

We first asked whether IE protein contains a transcriptional activation region comparable to that found in typical eukaryotic activators. We fused IE protein to the minimal DNA-binding region of the yeast GAL4 protein (amino acids $1-147$ ). Transcriptional activation by this GAL4-IE fusion protein was assayed after cotransfection with a chloramphenicol acetyltransferase (CAT) reporter plasmid whose promoter contained GAL4-binding sites upstream of a TATA box. Figure 1 shows that GAL4-IE stimulated transcription 260-fold from the GAL4 site-containing promoter. To obtain this high level of transcription required that the promoter contain GAL4-binding sites and that the IE protein be fused to the GAL4 DNA-binding domain. (To compensate for possible differences in expression levels between the IE and GAL4-IE proteins, a wide range of expression plasmid amounts have been transfected. Fig. 1 shows the maximum level of transcriptional activation observed.)

The IE protein transcriptional activation region is contained within amino acids 1-34

We then localized the region of the IE protein responsible for transcriptional activity by analyzing a series of GAL4-IE derivatives. In the course of these studies we found that transcription was inhibited upon transfection of high amounts of DNA expressing the GAL4-IE derivative. As discussed in detail below, we believe that the inhibition of transcription at high levels of activator is due to "squelching" (see Ptashne 1988). Thus, to quantitate the true activity of a GAL4-IE derivative requires that a range of activator amounts be tested. In the following experiment and in those depicted in Figures 1, 3, and 4 , the data presented represent the maximum level of transcription observed for a particular GAL4-IE derivative.

The results shown in Figure 2 summarize the activity of a series of carboxy-terminal and amino-terminal deletion mutants. These and all other GAL4-IE derivatives described here are produced at comparable levels (within two- to threefold), as determined by immunoblot analysis (data not shown). Successive carboxy-terminal deletions, removing amino acids 1460 to 34 of IE protein, resulted in steadily increasing levels of transcriptional activity. The carboxy-terminal deletions interfere with transcriptional activation when amino acids beyond residue 34 are removed. All amino-terminal deletions, including the removal of IE protein amino acids $1-3$, interfere with transcriptional activity (Fig. 2). Thus, a small region of the IE protein, amino acids $1-34$, comprises a remarkably potent activation region that can stimulate transcription 755 -fold. This level of activation is comparable to that of the notoriously potent HSV-1 VP16 activation region (Sadowski et al. 1988; Triezenberg et al. 1988). The unusually high activity of IE protein amino acids $1-34$ strongly suggests that it is a genuine activation region and not merely a sequence that
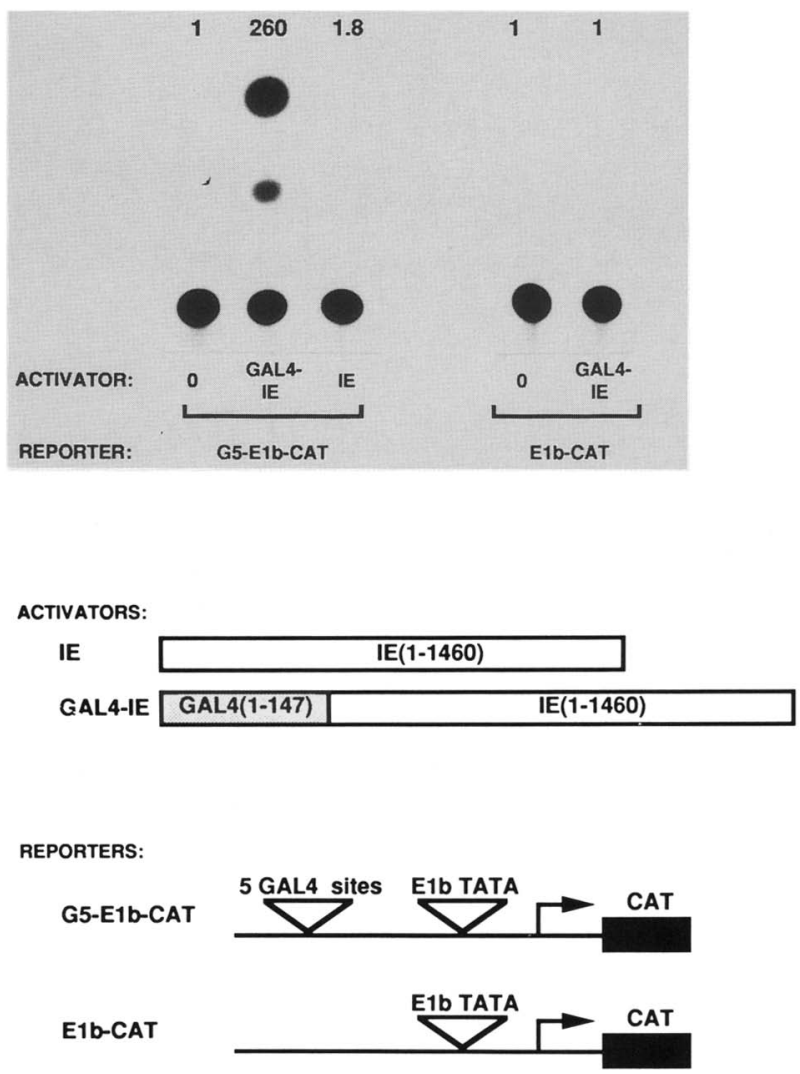

Figure 1. IE protein activates transcription when bound near a promoter. A reporter CAT plasmid containing a core promoter (ElbTATA box) and either none or five GAL4 sites was cotransfected with a range of amounts $(0.01-3 \mu \mathrm{g})$ of the activator plasmid DNA indicated. Cells were harvested $48 \mathrm{hr}$ postDMSO shock. CAT activity was quantitated, and levels (relative to basal level) are indicated above each lane. The data shown for lanes 2 and 3, (left) and lane 2 (right) represent the maximum level of activation observed across the range of plasmid amounts transfected. These lanes represent $1 \mu \mathrm{g}$ plasmid DNA. Structures of the activator proteins and reporter plasmids are diagramed below.

functions adventitiously when fused to the GAL4 DNAbinding domain. This conclusion is verified by experiments presented below.

IE protein amino acids 1-34 are critical for activation of promoters that lack GAL4 sites

We then tested whether IE protein amino acids 1-34 are required for transcriptional activity when IE protein is not directed to a promoter via the GAL4 DNA-binding domain. We used the adenovirus E4 promoter as a reporter, which lacks GAL4-binding sites and is strongly activated by the normal IE protein (Ihara et al. 1983; Fig. 3). Figure 3 (left) shows that, as expected, both IE and GAL4-IE proteins activated transcription from E4CAT. Because the E4 promoter lacks GAL4 sites, the GAL4 (1-147) sequences in GAL4-IE are irrelevant. In the following experiment GAL4 sequences are included to (1) ensure that all IE protein derivatives have the same 
Figure 2. Mapping of the activation region of IE protein. A reporter CAT plasmid containing a core promoter (ElbTATA box) and five GAL4 sites (diagramed at bottom / was cotransfected with a range of amounts $(0.01-3 \mu \mathrm{g})$ of activator plasmid DNA. Cells were harvested $48 \mathrm{hr}$ post-DMSO shock. Relative CAT activity was quantitated and is indicated next to the diagramed activators. The data shown represent the maximum level of activation observed across the range of plasmid amounts transfected $(0.1-1 \mu \mathrm{g})$. The GAL4 fusion proteins are all expressed at equivalent levels /within two- to threefold) in CHO cells (data not shown).
ACTIVATORS:

GALA-IE (1-580)

GALA-IE $\{1-330)$

GALA-IE (1-137)

GAL4-IE (1-64)

GALA-IE (1-34)

GAL4-IE (1-20)

GALA-1E (1-16)

GAL-1E (4-580)

GAL4-IE (13-580)

\begin{tabular}{|l|l|}
\hline GAL4(1-147) & IE(1-580) \\
\hline
\end{tabular}

\begin{tabular}{|l|l|}
\hline GAL4(1-147) & IE(1-330) \\
\hline
\end{tabular}

(1)

\begin{tabular}{|l|r|}
\hline GAL4(1-147) & IE(1-137) \\
\hline
\end{tabular}

$\square$

\begin{tabular}{|l|l|}
\hline GAL4(1-147) & IE(1-64) \\
\hline
\end{tabular}

\begin{tabular}{|l|l|}
\hline GAL4(1-147) & IE(1-34) \\
\hline
\end{tabular}

\begin{tabular}{|l|l|}
\hline GAL4(1-147) & IE(1-20) \\
\hline
\end{tabular}

\begin{tabular}{|l|l|}
\hline GAL4(1-147) & IE(1-16) \\
\hline
\end{tabular}

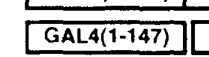

GAL4(1-147)

\begin{tabular}{|c|}
\hline $\mathrm{IE}(4-580)$ \\
\hline $\mathrm{IE}(13-580)$ \\
\hline
\end{tabular}

CAT Activity

270

310

460

495

755

16

2.5

93

REPORTER:

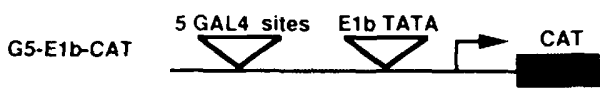

amino-terminal sequence, an important determinant of protein stability (Bachmair et al. 1986; Slavicek et al. 1988); and (2) facilitate specific control experiments.

Deletion of the first 29 or 76 amino acids of IE protein results in GAL4-IE derivatives, GAL4-IE (30-1460) and GAL4-IE (77-1460), which fail to activate E4 transcription. A control experiment (Fig. 3, right) indicates that GAL4-IE $(30-1460)$ was stably produced and present in the nucleus: Expression of GAL4-IE $(30-1460)$ inhibited activation by GAL4-IE $(1-34)$ on a reporter that contained GAL4-binding sites. The stable expression of GAL4-IE $(30-1460)$ was also demonstrated by immunoblot analysis (data not shown).

The IE protein is directed to the vicinity of a promoter in vivo

A typical transcriptional activation region functions only if it can be targeted to a promoter (for review, see Ptashne 1988). We then asked whether IE protein contained the second hallmark of cellular activators, a promoter-targeting region. We tested the ability of an IE protein derivative that lacks its own activation region to direct an unrelated acidic activation region to a promoter. A similar strategy was used to show that the adenovirus Ela protein contains a promoter-targeting activity (Lillie and Green 1989).

Figure 4 shows that addition of the HSV-1 VP16 activation region restored the ability of GAL4-IE (30-1460) to stimulate transcription. Because the reporter used in this experiment, E4-CAT, lacks GAL4-binding sites, the IE portion of the fusion protein must have provided the promoter-targeting function. The level of activation by GAL4-IE-VP16 (27-fold) is comparable to that of the intact IE protein (44-fold; Fig. 3). We conclude that IE protein contains a region that can direct itself, or an unrelated activation region, to the vicinity of the promoter. We conclude further that the transcriptional activation and promoter-targeting regions of IE protein do not overlap: GAL4-IE (30-1460), which lacks the activation region, can direct the VP16 activation region to the promoter.
To begin to identify the region of the IE protein responsible for promoter targeting, we tested the ability of an IE protein deletion mutant to activate transcription of E4-CAT. Figure 4 shows that GAL4-IE $\{1-580\}$ fails to activate E4-CAT transcription efficiently. Because the activation region of GAL4-IE $(1-580)$ is intact (Fig. 2 ), its inability to activate $\mathrm{E} 4$ transcription must reflect the absence of an intact promoter-targeting region. We conclude that the IE protein promoter-targeting region is dependent upon amino acids 580-1460.

\section{Evidence that the IE transcriptional activation region interacts with the same cellular target as an acidic activator}

The amino acid sequence of the IE transcriptional activation region identified here is shown in Figure 5. Of the 34 amino acids, 8 are negatively charged, suggesting that the IE protein activation region is of the acidic class. We performed squelching experiments to support this idea. Overexpression of an activation region can inhibit the activity of another activator (Gill and Ptashne 1988; Sadowski et al. 1988; Triezenberg et al. 1988). This inhibition, termed squelching, is thought to result from titration of the cellular target of the activation region. Squelching experiments have been used to compare the targets of various transcriptional activators (Meyer et al. 1989; Berger et al. 1990; Kelleher et al. 1990; Martin et al. 1990$)$.

We compared the target of the IE activation region with those of an acidic activator, VP16 (Triezenberg et al. 1988), and a nonacidic activator, Ela (Martin et al. 1990). In these experiments, an intact activator is co-expressed with an excess of a protein that cannot target to that promoter. If both proteins interact with the same cellular factor, the overexpressed protein will sequester the cellular factor, inhibiting the intact activator /for review, see Ptashne 1988; Gill and Ptashne 1988; Martin et al. 1990).

In Figure 6A two fusion proteins are used: GAL4-IE $(1-64)$ and LexA-VP16. Both of these fusion proteins can activate promoters containing the appropriate 

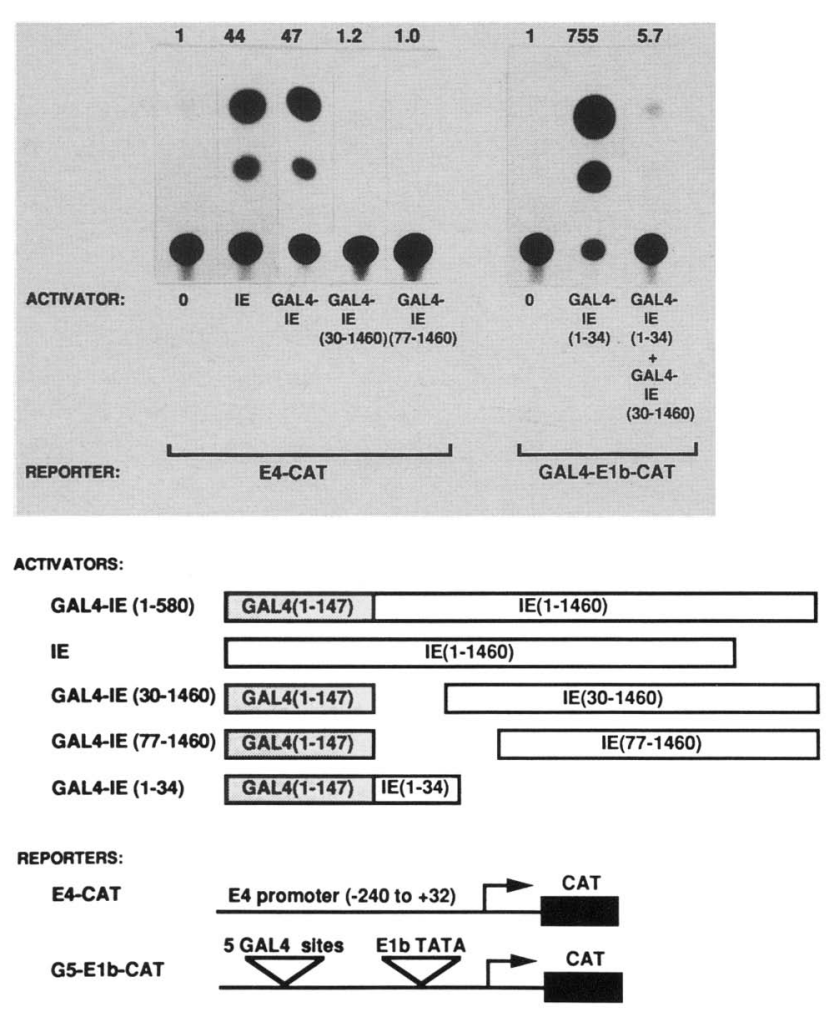

Figure 3. The IE protein activation region is critical to the functioning of wild-type IE protein. (Left) The effect of deleting the activation region of the IE protein. A reporter CAT plasmid containing the adenovirus E4 promoter was cotransfected with a range of amounts $(1 \mathrm{ng}-1 \mu \mathrm{g})$ of the activator plasmid DNA indicated and diagramed below. Cells were harvested $48 \mathrm{hr}$ post-DMSO shock. CAT activity was quantitated, and levels (relative to basal level) are indicated above each lane. (Left) The data shown for lanes 2-5 represent the maximum level of activation observed across the range of plasmid amounts transfected. These lanes represent $10 \mathrm{ng}$ plasmid DNA for IE protein, and $0.1-1 \mu \mathrm{g}$ for the GAL4 derivatives. (Right) A control showing that GAL4-IE $(30-1460)$ is expressed and is functional in this experiment. A reporter CAT plasmid containing the EIbTATA box and five GAL4 sites was cotransfected with $0.3 \mu \mathrm{g}$ of the activator plasmid GAL4-IE $(1-34)$. (Lane 3) Cotransfection of $3 \mu \mathrm{g}$ GAL4-IE (30-1460). Transfections contained equal amounts of plasmid DNA by adding appropriate vectors. Cells were harvested $56 \mathrm{hr}$ post-DMSO shock, and CAT activity is indicated above each lane.

binding sites. Likewise, both can be used as inhibitors (squelchers) if the reporter lacks such binding sites. Figure 6A shows that VP16 can inhibit activation by IE (left), and conversely, IE can inhibit activation by VP16 (right). These results suggest that the IE activation region uses the same cellular target as the acidic activator VP16.

Figure $6 \mathrm{~B}$ presents squelching experiments using the activation regions of IE and Ela proteins. We have shown previously that the target of the activation region of Ela is an auxiliary cellular factor, which is not required by acidic activators (Martin et al. 1990). As described above, both GAL4-IE $(1-64)$ and LexA-Ela can be used as activators if the reporter contains the appro- priate binding sites. The intact 289 -amino-acid Ela protein contains a potent transcriptional activation region but cannot activate the GAL4 site reporter because it lacks the appropriate targeting function (Lillie and Green 1989). Ela protein can therefore be used as a potential inhibitor (squelcher). Figure 6B shows that Ela protein does not inhibit activation by IE protein, whereas IE protein inhibits activation by LexA-Ela. These results are analogous to those observed previously in squelching experiments using Ela protein and VP16 (Martin et al. 1990) and further support the conclusion that the acidic IE and VPl 6 activation regions interact with a common cellular target.

\section{Discussion}

In general, cellular transcriptional activators are sequence-specific DNA-binding proteins. Their mode of action is highly specific; they can activate only those promoters that bear the appropriate binding sites. In contrast, the pseudorabies virus IE protein is a promiscuous activator of viral and cellular gene transcription. Nevertheless, here we show that IE protein has the two essential features of typical cellular activators: a transcriptional activation region and a promoter-targeting region. Both of these regions are required for activation by the intact IE protein. These results indicate that IE protein activates transcription by a mechanism analogous to that of a typical cellular activator.

IE protein amino acids $1-34$ comprise a relatively
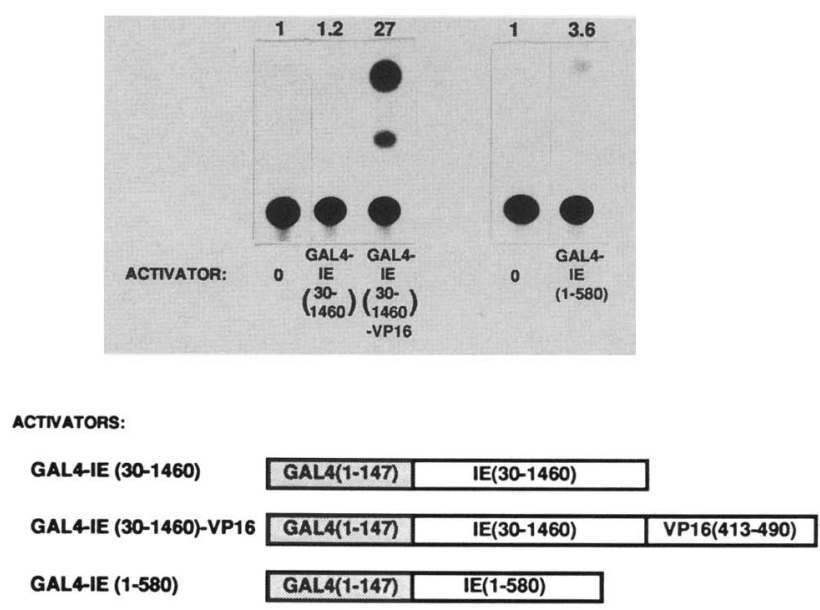

REPORTER: E4-CAT

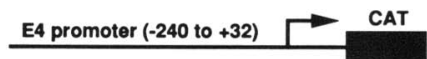

Figure 4. Substitution of the activation region of VP16 for the activation region of the IE protein. A reporter CAT plasmid containing the adenovirus $\mathrm{E} 4$ promoter was cotransfected with a range of amounts $(1 \mathrm{ng}-1 \mu \mathrm{g})$ of the activator plasmid DNA indicated. Cells were harvested $48 \mathrm{hr}$ post-DMSO shock. CAT activity was quantitated, and levels (relative to basal level) are indicated above each lane. The data shown for lanes 2 and 3 (left) and lane 2 (right) represent the maximum level of activation observed across the range of plasmid amounts transfected. These lanes represent $\sim 0.1 \mu \mathrm{g}$ plasmid DNA. 


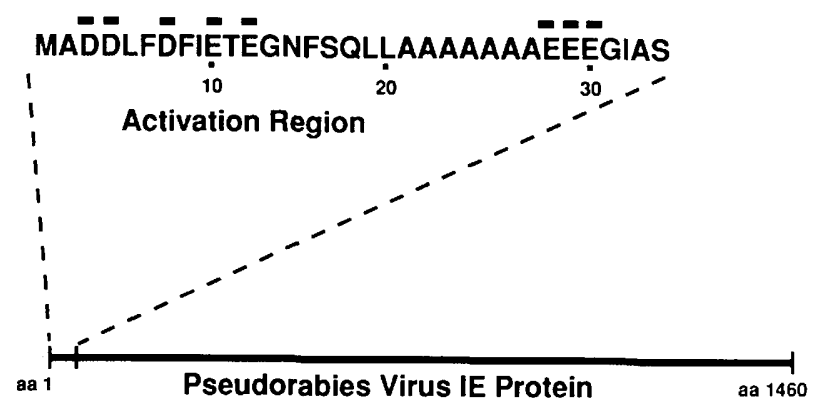

Figure 5. Amino acid sequence of the activation region of the IE protein. Line at bottom represents the full-length, 1460amino-acid IE protein. Sequence at top represents an expanded view of the 34-amino-acid activation region of the IE protein. Acidic residues are indicated by negative signs above the letters.

small and unusually potent transcriptional activation region. Previously identified activation regions vary from $\sim 30$ to 100 residues in length (for review, see Mitchell and Tjian 1989). Activation regions as short as that of IE protein include the 35 - to 40 -residue GCN4

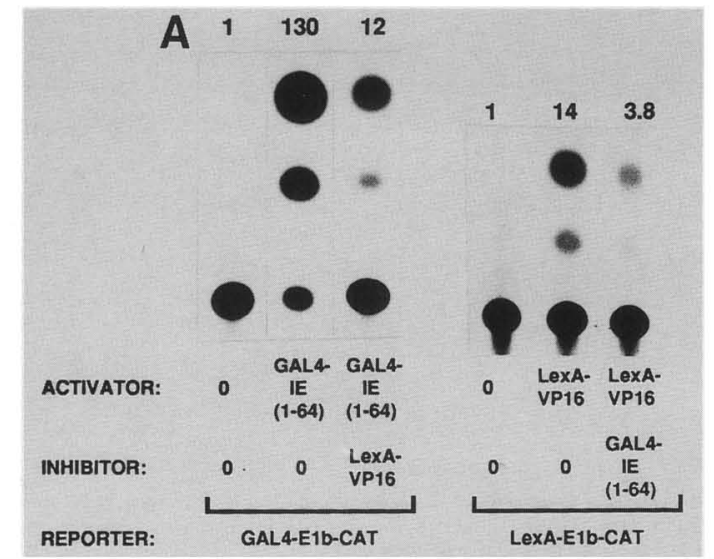

ACTIVATORS / INHIBITORS:

GAL4-IE (1-64)

\begin{tabular}{|l|l|}
\hline GAL4(1-147) & IE(1-64) \\
\hline
\end{tabular}

LexA-VP16

\begin{tabular}{|l|l|}
\hline LexA(1-202) & VP16(413-490) \\
\hline
\end{tabular}

REPORTERS:

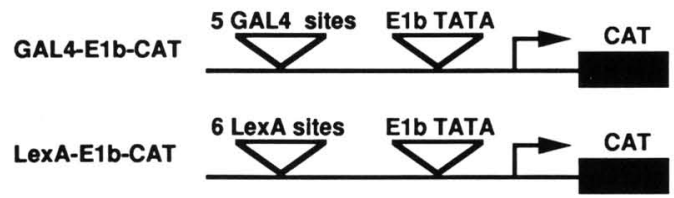

region (Hope et al. 1988), the 32-residue region of adenovirus Ela protein (Lillie and Green 1989; Martin et al. 1990 ), and a 15-residue, synthetic, amphipathic $\alpha$-helical peptide (Giniger and Ptashne 1987). The strength of the IE protein activation region is unusual and comparable to that of the strongest known activator VP16 (Sadowski et al. 1988; Triezenberg et al. 1988).

The IE protein activation region is relatively acidic, having a net charge of -8 . This is comparable to that of activators for which net acidity has been shown to be the critical determinant of activation potential (GCN4, VP16, and GAL4; for review, see Mitchell and Tjian 1989|. Other activation motifs, such as prolines /CTF/ $\mathrm{NF}-\mathrm{I})$, glutamines $(\mathrm{Spl}$; for review, see Mitchell and Tjian 1989), or a metal-binding site (Ela; Lillie and Green 1989; Martin et al. 1990), are not apparent within these 31 amino acids. Thus, it appeared likely that the IE protein activation region would use the same target as the acidic activators, an expectation supported by our squelching experiments.

A variety of studies indicate that acidic activators interact with a basic transcription factor or a protein tightly associated with such a factor (for review, see
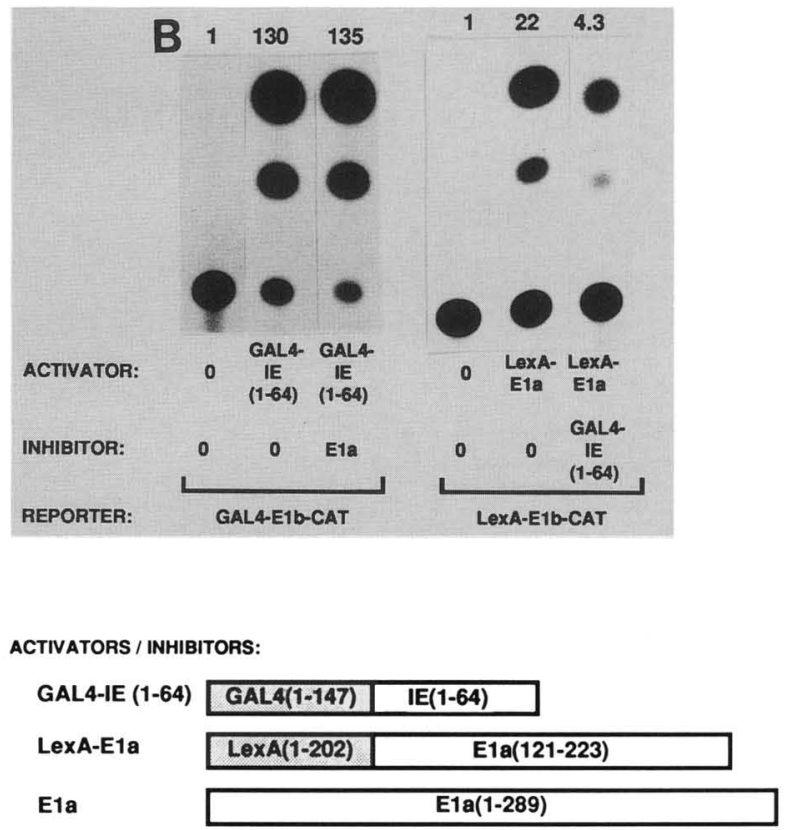

REPORTERS:

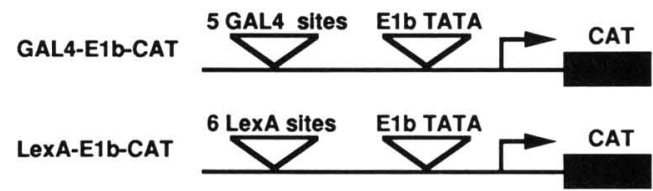

Figure 6. Interaction of the IE protein with the same target as that of an acidic activator. (A) Squelching of IE protein by VP16 (left); squelching of VP16 by IE protein (top right). A reporter CAT plasmid containing the ElbTATA box and five GAL4 sites or six LexA sites was cotransfected with $30 \mathrm{ng}$ GAL4-IE $(1-64)$ or $50 \mathrm{ng}$ LexA-VP16 as indicated and, where indicated, $3 \mu \mathrm{g}$ of inhibitor plasmid. Each transfection in these experiments contained equal amounts of plasmid DNA due to the addition of appropriate vectors. Cells were harvested $56 \mathrm{hr}$ post-DMSO shock. CAT activity was quantitated and is indicated above each lane. $(B)$ Squelching of IE protein by Ela protein (top left); squelching of Ela protein by IE protein (top right). Details are the same as for $A$. Where indicated, transfections contained, $0.4 \mu \mathrm{g}$ LexA-E $1 \mathrm{a}$ or $30 \mathrm{ng}$ GAL4-IE (1-64) activator plasmid DNAs and $3 \mu \mathrm{g}$ GAL4-IE $(1-64)$ or $3 \mu \mathrm{g}$ E $1 \mathrm{a}$ protein inhibitor DNAs. 
Lewin 1990; Ptashne and Gann 1990|. We have shown that the IE protein contains an acidic transcriptional activation region and is thus likely to interact with a basic transcription component. Abmayr et al. $(1985,1988)$ found that IE protein increases the rate (or extent) of formation of a complex containing TFIID and promoter DNA. This is consistent with the possibility that the IE protein activation region interacts with TFIID or a protein tightly associated with TFIID.

Pseudorabies is a member of the herpes virus family. This family includes several viruses known to produce IE proteins with characteristics analogous to those of the pseudorabies virus IE protein. DNA sequence comparisons have revealed extensive regions of homology among the activator proteins of herpes simplex, varicellar zoster, and pseudorabies viruses (Cheung 1989). Surprisingly, the activation region of pseudorabies IE protein lies outside any of these highly homologous regions. A possible explanation is that the sequence requirements of acidic activators are not rigid ( $\mathrm{Ma}$ and Ptashne 1987; Hope et al. 1988; for review, see Ptashne 1988 ) and, thus, may not be readily identified by homology searches.

The ability of IE protein to activate transcription promiscuously would appear to lie in its promoter-targeting region. In this regard, the recent studies by Cromlish et al. (1989) are particularly relevant. These investigators used DNase I footprinting experiments to show that partially purified IE protein can bind directly to multiple, apparently unrelated DNA sequences (Cromlish et al. 1989). Moreover, addition of oligonucleotides containing these binding sites prevented IE protein from activating transcription in vitro. Our in vivo results show that IE protein contains a region capable of directing a heterologous activation region to a promoter. This promoter-targeting function depends on residues located in the carboxy-terminal half of the IE protein. We propose that this region of IE protein functions by binding directly to diverse DNA sequences, thereby positioning the potent IE transcriptional activation region within the vicinity of a wide variety of promoters. Thus, promiscuous activation by IE protein can be explained in a manner consistent with established paradigms of typical eukaryotic activators.

\section{Materials and methods}

\section{Reporter plasmids}

Each GAL4-binding site is the 17-bp oligonucleotide (MH100) described previously (Webster et al. 1988) and is inserted immediately upstream of each target promoter, as indicated (Lillie and Green 1989). The E4-CAT plasmid (Lillie and Green 1989) contains Ad5 E4 sequences from -240 to +32 |relative to the transcription initiation site) inserted upstream of the CAT gene in a pSP72 vector (Promega Biotec). The ElbTATA promoter contains an oligonucleotide comprising the E1b TATA box $15^{\prime}$ AGGGTATATAATG-3') inserted immediately upstream of the CAT gene in pSP72 (Lillie and Green 1989). The LexAElbTATA reporter (pL6EC) (gift of P. Broad) has a triplicated insert of a fragment containing two LexA sites (Ebina et al.
1983 in the upstream polylinker of the ElbTATA reporter (Martin et al. 1990).

\section{Activator plasmids}

Wild-type IE protein is the 1460 -amino-acid pseudorabies IE protein (Cheung 1989) expressed from the plasmid pSIE, which contains the SV40 early promoter of the pECE expression vector (Ellis et al. 1986). GAL4 (1-147) comprises GAL4 amino acids $1-147$ and is expressed from plasmid pSG147 or pSG424 (Sadowski et al. 1988). GAL4-IE (pSGIE-DdeI) is IE protein amino acids $1-1460$ fused in-frame to the carboxyl terminus of GAL4 (1-147). An additional four amino acids (PEFP) are expressed between GAL4 and IE and are encoded by the polylinker of pSG424. pSGIE-DdeI was constructed by linking the NcoI-DdeI fragment of pSIE (Cheung 1989) downstream of GAL4 $(1-147)$ at the SmaI site of pSG424. GAL4-IE $\triangle$ C580, GAL4-IE $\Delta$ C330, GAL4-IE $\Delta$ C137, GAL4-IE $\Delta$ C64, GAL4IE $\Delta \mathrm{C} 34, \mathrm{GAL} 4-\mathrm{IE} \Delta \mathrm{C} 20$ and GAL4-IE $\Delta \mathrm{Cl} 6$ are progressive $3^{\prime}$ BAL-31 deletions of PSGIE-DdeI.

The GAL4-IE $\Delta N$ deletions are progressive 5' BAL-31 deletions of the IE DdeI fragment or of GAL4-IE $\Delta$ C 580 , fused in frame to GAL4 (1-147). GAL4-IE $(30-1460)-$ VP16 contains the 78 carboxy-terminal amino acids of the HSV VP16 protein fused in-frame to the carboxyl terminus of GAL4-IE $(30-1460)$.

LexA-Ela is Ela protein amino acids 121-223 fused inframe to the carboxyl terminus of LexA 11-202; Martin et al. 1990). LexA-VP16 (a gift of P. Broad) contains the 78 carboxyterminal amino acids of HSV-1 VP16 protein fused in-frame to the carboxyl terminus of LexA (1-202; Martin et al. 1990).

\section{Transfections and CAT assays}

The reporter $(1 \mu \mathrm{g})$ and a specified amount of the activator plasmid were transfected by the DEAE-dextran technique (Cato et al. 1986) into Chinese hamster ovary (CHO-DUKX) cells. Cells were maintained below $60 \%$ confluency in $\alpha$-MEM plus nucleotides and were split $1: 8$ at $24 \mathrm{hr}$ or $1: 4$ at $6 \mathrm{hr}$ before transfection. Cells were harvested 48 or $72 \mathrm{hr}$ postDMSO shock and assayed for CAT activity as described (Gorman et al. 1982). After autoradiography of the separated acetylated chloramphenicol forms, spots were excised and quantitated by liquid scintillation counting. In place of internal controls for transfection efficiency, all assays presented have been repeated at least twice with comparable results.

\section{Immunoblotting}

CHO cells were transfected as described above with $10 \mu \mathrm{g}$ of activator plasmid DNA. Cells were harvested $72 \mathrm{hr}$ after DMSO shock. Lysed cell supernatant $(20 \mu l)$ was electrophoresed on a polyacrylamide gel. After transfer of the separated proteins onto nitrocellulose membrane and blocking with milk solution, the proteins were incubated with $\alpha$-GAL4 antibody (gift of I. Sadowski), rinsed, incubated with ${ }^{125}$-labeled protein A (NEN), anc rinsed again. The GAL4 derivatives were visualized by autoradiography.

\section{Acknowledgments}

This work was supported by the National Institutes of Health (M.R.G.). K.J.M. is a fellow of the Jane Coffin Childs Memorial Fund for Medical Research. This investigation was also aided by a grant from the Jane Coffin Childs Memorial Fund for Medical Research. 
The publication costs of this article were defrayed in part by payment of page charges. This article must therefore be hereby marked "advertisement" in accordance with 18 USC section 1734 solely to indicate this fact.

\section{References}

Abmayr, S.M., L.D. Feldman, and R.G. Roeder. 1985. In vitro stimulation of specific RNA polymerase II-mediated transcription by the pseudorabies virus immediate early protein. Cell 43: 821-829.

Abmayr, S.M., J.L. Workman, and R.G. Roeder. 1988. The pseudorabies immediate early protein stimulates in vitro transcription by facilitating TFIID : promoter interactions. Genes Dev. 2: 542-553.

Ahlers, S.E. and L.T. Feldman. 1987. Effects of a temperaturesensitive mutation in the immediate-early gene of pseudorabies virus on class II and class III gene transcription. I. Virol. 61: 1103-1107.

Bachmair, A., D. Finley, and A. Varshavsky. 1986. In vivo halflife of a protein is a function of its amino-terminal residue. Science 234: 179-186.

Berger, S.L., W.D. Cress, A. Cress, S.J. Treizenberg, and L. Guarente. 1990. Selective inhibition of activated but not basal transcription by the acidic activation domain of VP16: Evidence for transcriptional adaptors. Cell 61: 1199-1208.

Berk, A.J. 1986. Adenovirus promoter and Ela transactivation. Annu. Rev. Genet. 20: 45-79.

Cato, A., R. Miksicek, G. Schuz, J. Arnemann, and M. Beato. 1986. The hormone regulatory element of mouse mammary tumor virus mediates progesterone induction. EMBO $/$. 5: $2237-2240$.

Cheung, A.K. 1989. DNA nucleotide sequence analysis of the immediate-early gene of pseudorabies virus. Nucleic Acids Res. 17: 4637-4646.

Cromlish, W.A., S.M. Abmayr, J.L. Workman, M. Horikoshi, and R.G. Roeder. 1989. Transcriptionally active immediateearly protein of pseudorabies virus binds to specific sites on class II gene promoters. J. Virol. 63: 1869-1876.

Ebina, Y., Y. Takakara, F. Kishi, A. Nakazawa, and R. Brent. 1983. LexA protein is a repressor of the Culicin El gene. $I$. Biol. Chem. 258: 13258-13261.

Ellis, L., E. Clauser, D.O. Morgan, M. Edery, R.A. Roth, and W.J. Rutter. 1986. Replacement of insulin receptor tyrosine residues 1162 and 1163 compromises insulin-stimulated kinase activity and uptake of 2-deoxyglucose. Cell 45: 721732.

Feldman, L.T., M.J. Imperiale, and J.R. Nevins. 1982. Activation of early adenovirus transcription by the herpes virus. Proc. Nat1. Acad. Sci. 79: 4952-4956.

Gaynor, R.B. and A.J. Berk. 1983. Cis-acting induction of adenovirus transcription. Cell 33: 683-693.

Gill, G.M. and M. Ptashne. 1988. Negative effect of the transcriptional activator GAL4. Nature 334: 721-724.

Giniger, E. and M. Ptashne. 1987. Transcription in yeast activated by a putative amphipathic $\alpha$-helix linked to a DNAbinding unit. Nature 330: 670-672.

Gorman, C.M., L.F. Moffat, and B.H. Howard. 1982. Recombinant genomes which express chloramphenicol acetyl-transferase in mammalian cells. Mol. Cell. Biol. 2: 1044-1051.

Green, M.R., R. Treisman, and T. Maniatis. 1983. Transcriptional activation of cloned human $\beta$-globin genes by viral immediate-early gene products. Cell 35: 137-148.

Hope, I.A., S. Mahadevan, and K. Struhl. 1988. Structural and functional characterization of the short acidic transcriptional activation region of yeast GCN4 protein. Nature
333: $635-640$.

Ihara, S., L. Feldman, S. Watanabe, and T. Ben-Porat. 1983. Characterization of the immediate-early function of pseudorabies virus. Virology 131: 437-454.

Kelleher, R.J., P.M. Flanagan, and R.D. Kornberg. 1990. A novel mediator between activator proteins and the RNA polymerase II transcription apparatus. Cell 61: 1209-1215.

Lewin, B. 1990. Commitment and activation at Pol II promoters: A tail of protein-protein interactions. Cell 61: $1161-1164$.

Lillie, J.W. and M.R. Green. 1989. Transcription activation of the adenovirus Ela protein. Nature 338: $39-44$.

Liu, F. and M.R. Green. 1990. A specific member of the ATF transcription factor family can mediate transcription activation by the adenovirus Ela protein. Cell 61: 1217-1224.

$\mathrm{Ma}, \mathrm{J}$. and M. Ptashne. 1987. A new class of transcriptional activators. Cell 51: 114-119.

Martin, K.J., J.W. Lillie, and M.R. Green. 1990. Evidence for the interaction of different eukaryotic transcriptional activators with distinct cellular targets. Nature 345: 147-152.

Meyer, M.-E., H. Gronemeyer, B. Turcotte, M.-T. Bocquel, D. Tasset, and P. Chambon. 1989. Steroid receptors compete for factors that mediate their enhancer function. Cell 57: 433-442.

Mitchell, P.J. and R. Tiian. 1989. Transcriptional regulation in mammalian cells by sequence-specific DNA binding proteins. Science 245: 371-378.

Ptashne, M. 1988. How eucaryotic transcriptional activators work. Nature 335: 683-689.

Ptashne, M. and A.A.F. Gann. 1990. Activators and targets. Nature 346: 329-331

Sadowski, I., J. Ma, S. Triezenberg, and M. Ptashne. 1988. GAL4-VP16 is an unusually potent transcriptional activator. Nature 335: 563-564.

Slavicek, J.M., N.C. Jones, and J.D. Richter. 1988. Rapid turnover of adenovirus Ela is determined through a co-translational mechanism that requires an amino-terminal domain. $E M B O$ /. 7: 3171-3180.

Tevethia, M.J. and D.J. Spector. 1989. Heterologous transactivation among viruses. Prog. Med. Virol. 36: 120-190.

Tremblay, M.L., S.-P. Yee, R.H. Persson, S. Bacchetti, J.R. Smiley, and P.E. Branton. 1985. Activation and inhibition of expression of the 72,000-Da early protein of adenovirus type 5 in mouse cells constitutively expressing an immediate early protein of herpes virus type 1. Virology 144: 35-45.

Triezenberg, S., R. Kingsbury, and S. McKnight. 1988. Functional dissection of VP16, the trans-activator of herpes simplex virus immediate early gene expression. Genes Dev. 2: $718-729$.

Webster, N., J.R. Jin, S. Green, M. Hollis, and P. Chambon. 1988. The yeast $\mathrm{UAS}_{\mathrm{G}}$ is a transcriptional enhancer in human HeLa cells in the presence of the GAL4 trans-activator. Cell 52: $169-178$.

Yuan, R., C. Bohan, F.C.H. Shiao, R. Robinson, H.J. Kaplan, and A. Srinvason. 1989. Activation of HIV LTR-directed expression: Analysis with pseudorabies virus immediate early gene. Virology 172: 92-99. 


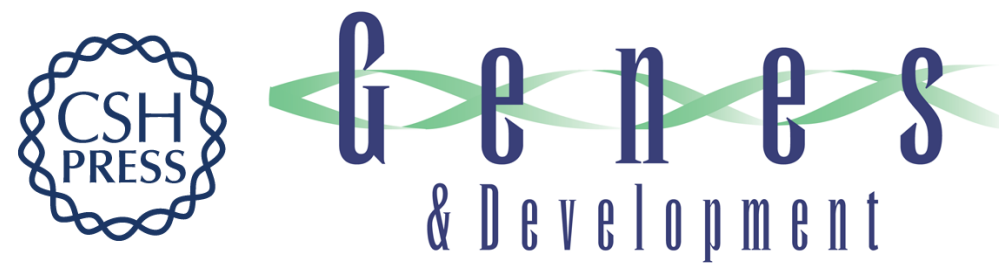

\section{Transcriptional activation by the pseudorabies virus immediate early protein.}

K J Martin, J W Lillie and M R Green

Genes Dev. 1990, 4:

Access the most recent version at doi:10.1101/gad.4.12b.2376

References This article cites 36 articles, 9 of which can be accessed free at:

http://genesdev.cshlp.org/content/4/12b/2376.full.html\#ref-list-1

License

Email Alerting

Service

Receive free email alerts when new articles cite this article - sign up in the box at the top right corner of the article or click here.

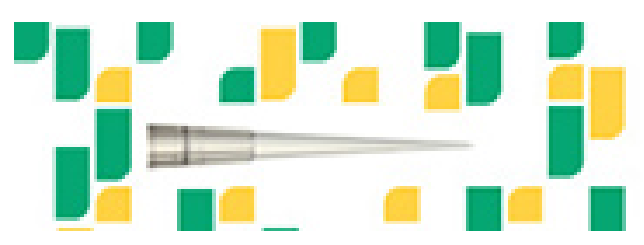

Focused on your science. 